\title{
Increase in chromogranin A- and serotonin-positive cells in pouch mucosa of patients with ulcerative colitis undergoing proctocolectomy
}

Running head: Neuroendocrine cells in pouch mucosa

Paolo Giuffrida ${ }^{1}$, Alessandro Vanoli ${ }^{2}$, Elena Biletta ${ }^{2}$, Catherine Klersy ${ }^{3}$, Gaetano Bergamaschi ${ }^{1}$, Gianluca M Sampietro ${ }^{4}$, Sandro Ardizzone ${ }^{5}$, Ombretta Luinetti², Michele Martino ${ }^{1}$, Marco Vincenzo Lenti ${ }^{1}$, Nicola Aronico ${ }^{1}$, Marco Curti ${ }^{1}$, Rachele Manca ${ }^{2}$, Paolo Fociani ${ }^{6}$, Marta Truffi ${ }^{7}$, Fabio Corsi ${ }^{7,8}$, Gino Roberto Corazza ${ }^{1}$, Antonio Di Sabatino ${ }^{1}$

From: Departments of ${ }^{1}$ Internal Medicine, ${ }^{2}$ Molecular Medicine, and ${ }^{3}$ Biometry and Clinical Epidemiology, San Matteo Hospital Foundation, University of Pavia, Pavia, Italy; ${ }^{4}$ IBD Surgical Unit, Divisions of ${ }^{5}$ Gastroenterology, ${ }^{6}$ Pathology, and ${ }^{7}$ Biomedical and Clinical Sciences "Luigi Sacco" University Hospital, Milan, Italy; Surgery Department, Breast Unit, IRCCS Maugeri, Pavia, Italy.

Word count: $\underline{2,960}$

Sources of funding, grant support

None

Financial disclosure

None

Abbreviations: CgA, chromogranin A; CD, Crohn's disease; EC, enterochromaffin; IBD, inflammatory bowel disease; IEL, intraepithelial lymphocyte; IL, interleukin; SERT, serotoninselective reuptake transporter; $\mathrm{TpH}$, tryptophan hydroxylase; TNF, tumor necrosis factor; UC, ulcerative colitis.

Keywords: chromogranin A; Crohn's disease; pouchitis; serotonin; ulcerative colitis.

Address for correspondence: Prof. Antonio Di Sabatino, Clinica Medica I, Fondazione IRCCS Policlinico San Matteo, Università di Pavia, Piazzale Golgi 19, 27100 Pavia, Italy. Phone: +39 0382 502973; Fax: +39 0382 502618; E-mail: a.disabatino@smatteo.pv.it 


\section{Abstract}

Background: Inflammatory bowel disease (IBD) is associated with neuroendocrine cell hyperplasia. Aims: We investigated neuroendocrine cells in J-pouches of patients with ulcerative colitis undergoing restorative proctocolectomy and ileal pouch-anal anastomosis. Methods: Sections from pouch biopsies of 17 patients and ileal biopsies of 17 active IBD patients and 16 controls were processed by immunohistochemistry for chromogranin $\mathrm{A}(\mathrm{CgA})$ and serotonin. Mucosal tryptophan hydroxylase $(\mathrm{TpH})-1$ and serotonin-selective reuptake transporter (SERT) transcripts were measured by quantitative RT-PCR. TpH-1 and SERT transcripts were detected in pouch biopsies cultured with infliximab or its isotype control, while IL-6 and IL-8 were measured in biopsy supernatants. Results: A significant increase in CgA-positive cells and serotonin-positive cells was observed in both pouch and IBD ileum compared to control ileum. Significantly raised transcripts of $\mathrm{TpH}-1$, but not SERT, were found in IBD ileum in comparison to control ileum, with no significant difference between pouch and IBD ileum. Infliximab had no influence on ex vivo pouch expression of TpH-1 and SERT, nor on the production of IL-6 and IL8. Conclusion: We here demonstrated neuroendocrine cell hyperplasia in pouch mucosa. Further studies are needed to clarify the pathophysiological implication of this finding. 


\section{Introduction}

Abnormal amount and functioning of neuroendocrine cells, which comprise at least 14 cytotypes and express the pan-neuroendocrine marker chromogranin $A(\mathrm{CgA})$, have been reported in several animal models of colitis ${ }^{1,2}$ and immune-mediated intestinal disorders, including Crohn's disease (CD), ${ }^{3-5}$ ulcerative colitis $(U C)^{5-11}$ and celiac disease. ${ }^{12}$ However, how neuroendocrine cells modulate the inflammatory response in the aforementioned disorders is largely unknown. The dominant cytotype among the CgA-positive neuroendocrine cells populating the bowel mucosa is represented by serotonin-producing enterochromaffin (EC) cells. ${ }^{13}$ There is evidence that serotonin induces T-cell proliferation ${ }^{14}$ and dendritic cell activation, ${ }^{15}$ sustains immune-cell recruitment, ${ }^{16}$ and up-regulates pro-inflammatory cytokine production. ${ }^{17}$ In active celiac duodenal mucosa, EC cells are increased and serotonin stimulates interferon- $\gamma$ production by treated celiac biopsies grown ex vivo. ${ }^{12}$

A number of studies have been published investigating neuroendocrine cells in the pouch mucosa of UC patients undergoing restorative proctocolectomy and ileal pouch-anal anastomosis (Table 1). In particular, neurotensin-, polypeptide YY- and enteroglucagon-positive cells were found to be reduced in pouch biopsies, ${ }^{18,19}$ while serotonin was over-expressed in the pouch mucosa of patients with irritable pouch syndrome. ${ }^{20}$ In contrast, no difference was observed by Pietroletti et al. ${ }^{19}$ in the mucosal expression of serotonin in pouchitis.

Based on these premises, we aimed to investigate neuroendocrine cells in the pouch mucosa of patients with ulcerative colitis who underwent restorative proctocolectomy, and to assess mucosal tryptophan hydroxylase $(\mathrm{TpH})-1$, which is an enzyme involved in serotonin synthesis, and serotonin-selective reuptake transporter (SERT) transcripts both in vivo and following downregulation of inflammation obtained through tumor necrosis factor (TNF)- $\alpha$ blockade by 
infliximab in ex vivo cultured pouch biopsies.

\section{Methods}

Patients and tissues. Endoscopic biopsy specimens were collected from J-pouches performed in 17 UC patients undergoing restorative proctocolectomy and ileal pouch-anal anastomosis (mean age 46.1 years, range 26-64). At biopsy collection, J-pouches had been followed-up for at least two years. None of the patients with pouch had extra-intestinal manifestations or relevant co-morbidities. In particular, coeliac disease was ruled out in all patients (negative anti-human tissue transglutaminase $\lg \mathrm{A}$ and normal serum $\lg \mathrm{A}$ ). All patients with pouch had been treated with courses of probiotics during the year before the study, and none was being treated with antibiotics at the time of biopsy collection. Clinical, endoscopic and pathological features of patients with pouch are reported in Table $2 .{ }^{21}$ The severity of pouch histological inflammation was assessed using Moskowitz criteria, ${ }^{22}$ including both acute (neutrophilic infiltration and ulcerations) and chronic (lymphoplasmacellular infiltration in the lamina propria and colonic metaplasia) changes. No case of irritable pouch syndrome was included. lleal biopsy samples were obtained from 17 active IBD patients (mean age 39.7 years, range 19-65). Amongst these patients, eight were affected by CD with ileal involvement and nine by UC with backwash ileitis. The mean grade of their histological inflammation was 4.6 (range $3-8$ ) in $C D$ and 1.1 (range 1-2) in UC according to the scoring system developed by Naini and Cortina. ${ }^{23}$ Two CD patients and one UC patient suffered from concomitant spondyloarthritis. Other co-morbidities included benign essential hypertension in two CD patients, autoimmune hemolytic anaemia in one UC patient and non-alcoholic fatty liver disease in two UC patients. As regards smoking habit, one CD patient and one UC patient were current smokers. Amongst the eight CD patients, three were treated with mesalazine, one with steroids, two with antibiotics, four with thiopurines and one with methotrexate. Amongst the nine UC patients with backwash 
ileitis, nine were treated with mesalazine, four with steroids and two with thiopurines. Diagnosis of CD and UC was made according to clinical and histological criteria, and the site and extent of the disease were endoscopically confirmed. Mucosal samples were also collected endoscopically from normal ileum of 16 asymptomatic patients undergoing colonoscopy for colorectal cancer screening (mean age 52.2 years, range $36-68$ ) as controls. Informed consent was obtained in all cases and the study was performed according to the Helsinki Declaration. Some tissue samples were immediately fixed in $10 \%$ neutral buffered formalin and embedded in paraffin within $24 \mathrm{~h}$. Consecutive $4 \mu \mathrm{m}$-thick sections were cut from the selected blocks, mounted on electrostatic slides (Super Frost Plus, Menzel-Glaser, Germany) and dried overnight. After dewaxing and rehydration, sections were processed for routine histology and immunohistochemistry. Some other biopsies were used for quantitative RT-PCR or organ culture experiments. The study was authorized by the Ethical Committee of the "Luigi Sacco" University Hospital, Milan, Italy (protocol number 0002846).

Intraepithelial lymphocyte (IEL) counting. Histological evaluation of hematoxylin and eosin-stained sections of pouch biopsies was undertaken by two independent observers (AV and EB) who were blinded to all clinical information. In each specimen, IEL number was counted per 100 epithelial cells. For each case, five different counts were carried out and the mean number of IELs per 100 epithelial cells was recorded.

Immunohistochemistry. Serial sections were taken from paraffin blocks of pouch and ileal biopsies and stained with hematoxylin-eosin or with immunoperoxidase using anti-CgA antibody (1:9000 dilution; Dako Cytomation, Glostrup, Denmark) and anti-serotonin antibody (1:1000 dilution; Monosan, Uden, The Netherlands). Neuroendocrine cell assessment was performed by counting the number of $\mathrm{CgA}$-positive and serotonin-positive cells per 100 epithelial cells in welloriented crypts. For each case, five different counts were carried out and the mean number of 
CgA-positive and serotonin-positive cells per 100 crypt cells was finally recorded.

RNA extraction and analysis of mRNA expression by quantitative RT-PCR. Total RNA was extracted with the RNeasy mini-kit (Qiagen Sciences, Valencia, CA) according to the manufacturer's instructions. cDNA was synthesized using 200-400 ng total RNA and the Transcriptor High Fidelity cDNA Synthesis Kit (Roche Diagnostics, Mannheim, Germany) in a final volume of $20 \mu \mathrm{L}$. Amplifications were performed on a LightCycler 2.0 instrument (Roche Diagnostics) using the LightCycler TaqMan Master kit (Roche Diagnostics) and validated fluorogenic TaqMan Gene Expression Assays-on-Demand for TpH-1 (Hs00188220_m1) and SERT (Hs00169010_m1), both from Applied Biosystems (Foster City, CA). Expression levels were calculated with the $\Delta \Delta C_{T}$ method following normalization to the GAPDH housekeeping gene (Universal ProbeLibrary Human GAPDH Gene Assay, Roche Diagnostics).

Organ culture. Biopsies from patients with a pouch were placed in 24-well tissue culture plates (BD Biosciences, Oxford, UK; one biopsy per well) in $300 \mu$ l serum-free HL-1 medium (Cambrex Bio Science, Walkersville, MD), supplemented with $100 \mathrm{U} / \mathrm{ml}$ penicillin and $100 \mathrm{~g} / \mathrm{ml}$ streptomycin (Life Technologies Ltd, Paisley, UK), and cultured at $37^{\circ} \mathrm{C}, 5 \% \mathrm{CO}_{2}$ with the antiTNF-a monoclonal antibody infliximab (Remicade; Merck, Milan, Italy) or its isotype-matched control (human IgG1; Sigma-Aldrich, Poole, UK). All antibodies were used at a concentration of $10 \mu \mathrm{g} / \mathrm{ml}$. After 24h ex vivo culture, biopsies were collected in RNAlater until used for quantitative RT-PCR and supernatants were stored at $-70^{\circ} \mathrm{C}$ prior to ELISA.

ELISA. Interleukin (IL)-6 and chemokine IL-8 levels were measured in organ culture supernatants using the specific ELISA kit (R\&D Systems, Abingdon, UK), according to the manufacturer's instructions. 
Statistical analysis. All analyses were performed using Stata 14.2 (StataCorp, College Station, TX, USA). A 2-sided $p$-value $<0.05$ was considered statistically significant. The Bonferroni correction was used for post-hoc comparisons of pouch, UC, CD and control and the significance was set at 0.017 (2-sided). Continuous variables were described as median and $25^{\text {th }}-75^{\text {th }}$ percentiles. They were compared between groups (pouch/UC/CD/controls) with the Kruskal Wallis test. The Wilcoxon signed-rank test was used for paired comparisons of biomarkers levels within patients. Correlation between biomarkers were assessed with the Spearman $\mathrm{R}$, together with its $95 \%$ confidence interval $(95 \% \mathrm{Cl})$.

\section{Results}

Immunohistochemical detection of CgA and serotonin. Numerous CgA-positive cells were evident in the crypt epithelium of patients with pouch (Figure 1A), UC (Figure 1B) and CD ileum (Figure 1C). On the other hand, CgA-positivity was found in fewer cells localized in the crypts of control ileum (Figure 1D). As shown in Figure 2A, the number of CgA-positive cells per 100 crypt cells was significantly $(p<0.001)$ higher in the pouch mucosa (median $13.0 \%, 25^{\text {th }}-75^{\text {th }} 11.0-15.7$ ) in comparison to control ileum (median $6.6 \%, 25^{\text {th }}-75^{\text {th }} 5.1-8.8$ ). No significant difference was found between pouch mucosa and both UC (median $9.7 \%, 25^{\text {th }}-75^{\text {th }} 9.0-10.3$ ) and CD ileum (median $\left.9.1 \%, 25^{\text {th }}-75^{\text {th }} 7.9-12.8\right)$ (after Bonferroni correction), without a significant difference between UC and CD ileum. However, pooling together UC and CD, CgA-positive cells were significantly $(p=0.005)$ increased in IBD ileum (median $\left.9.7 \%, 25^{\text {th }}-75^{\text {th }} 8.0-11.0\right)$ in comparison to control ileum, without a significant difference between IBD ileum and pouch (data not shown). No significant difference was found between pouch mucosa of the four patients undergoing restorative proctocolectomy due to dysplasia or cancer (median $11.6 \%, 25^{\text {th }}-75^{\text {th }} 8.5-16.1$ ) and that of the 13 patients undergoing proctocolectomy for non-neoplastic causes (median $14.5 \%$, 
$\left.25^{\text {th }}-75^{\text {th }} 10.5-15.7\right)$. No significant correlation was found between the percentage of CgApositive cells and the degree of acute $\left(r_{s}=-0.0634 ; p=0.8088\right)$, chronic $\left(r_{s}=-0.3211 ; p=0.2088\right)$ or acute plus chronic inflammation $\left(r_{s}=-0.2913 ; p=0.2567\right)$ in pouch mucosa (data not shown). ${ }^{22}$ We also correlated the percentage of CgA-positive cells with the proportion of IELs infiltrating the pouch mucosa whose median number was 5.4\% (range 2.2-11.4); however, no significant correlation $\left(r_{s}=-0.1075 ; p=0.6813\right)$ was observed between these two parameters (data not shown).

Numerous serotonin-positive cells were evident in the crypt epithelium of patients with pouch (Figure 1E), UC (Figure 1F) and CD ileum (Figure 1G). On the other hand, serotonin-positivity was found in fewer cells localized in the villous and crypts compartments of control ileum (Figure 1H). As shown in Figure 2B, the number of serotonin-positive cells per 100 crypt cells was significantly higher in the pouch mucosa (median $7.2 \%, 25^{\text {th }}-75^{\text {th }} 5.5-10.0, p<0.001$ ), UC (median $8.2 \%, 25^{\text {th }}-75^{\text {th }} 7.2-8.6, p=0.006$ ) and CD ileum (median $7.0 \%, 25^{\text {th }}-75^{\text {th }} 5.6-11.2$, $\mathrm{p}=0.004$ ) in comparison to control ileum (median $4.4 \%, 25^{\text {th }}-75^{\text {th }} 3.4-6.2$ ), without a significant difference between pouch mucosa and both UC and CD ileum (after Bonferroni correction). No significant difference was found between UC and CD ileum (after Bonferroni correction). In addition, pooling together UC and CD, serotonin-positive cells were significantly $(p<0.001)$ increased in IBD ileum (median $7.6 \%, 25^{\text {th }}-75^{\text {th }} 6.5-8.6$ ) in comparison to control ileum, without a significant difference between IBD ileum and pouch (data not shown). No significant difference was found between pouch mucosa of the four patients undergoing restorative proctocolectomy due to dysplasia or cancer (median $6.5 \%, 25^{\text {th }}-75^{\text {th }} 5.6-8.7$ ) and that of the 13 patients undergoing proctocolectomy for non-neoplastic causes (median $7.8 \%, 25^{\text {th }}-75^{\text {th }} 5.2-10.1$ ). We found a significant, though weak, $\left(r_{s}=-0.4860 ; p=0.0479\right)$ negative correlation between the percentage of serotonin-positive cells and the degree of acute plus chronic inflammation in pouch mucosa (data not shown). Instead, no significant correlation was found between the 
percentage of serotonin-positive cells and the degree of acute $\left(r_{s}=-0.47 ; p=0.0568\right)$ or chronic inflammation scores $\left(r_{s}=-0.4219 ; p=0.0916\right)$ in pouch mucosa (data not shown). We also correlated the percentage of serotonin-positive cells with the proportion of IELs infiltrating the pouch mucosa, but we did not observe any significant correlation $\left(r_{s}=0.2299 ; p=0.3748\right)$ between these two parameters (data not shown). Finally, a significant, though moderate, positive correlation $\left(r_{s}=0.6233 ; p<0.0001\right)$ was observed in all patients and control subjects between the percentage of $\mathrm{CgA}$-positive cells and serotonin-positive cells (Figure 2C).

Mucosal TpH-1 and SERT transcripts. Using quantitative RT-PCR, we measured the transcript levels of $\mathrm{TpH}-1$ and SERT in the pouch mucosa of six patients undergoing restorative proctocolectomy, and in the ileal mucosa of six active IBD patients and ten control subjects. As shown in Figure 3A, TpH-1 transcript levels were significantly $(p<0.001)$ higher in IBD ileum in comparison to control ileum. No significant difference was found between pouch and both IBD and control ileum (after Bonferroni correction). SERT transcript levels did not significantly differ among all the aforementioned groups (Figure 3B).

Ex vivo effect of infliximab on $T p H-1$ and SERT transcripts and on IL-6 and IL-8 production. In order to investigate the effect of infliximab on serotonin, we measured $\mathrm{TpH}-1$ and SERT expression in the pouch biopsies obtained from five patients undergoing restorative proctocolectomy, and cultured ex vivo with infliximab or its isotype control (IgG1) (Figure 4A). Both TpH-1 and SERT transcript levels did not significantly differ between the biopsies cultured with infliximab in comparison to those cultured with IgG1.

In order to investigate the effect of infliximab on innate cytokine production, we measured IL-6 and IL-8 levels in the supernatant of mucosal pouch biopsy samples obtained from five patients undergoing restorative proctocolectomy and cultured ex vivo with infliximab or IgG1 (Figure 4B). 
IL-6 levels did not significantly differ in the supernatants of biopsies cultured with infliximab (mean $1497 \pm 1133 \mathrm{pg} / \mathrm{mL}$ ) in comparison to those cultured with $\operatorname{lgG} 1$ (mean $634 \pm 802 \mathrm{pg} / \mathrm{mL}$ ). Likewise, IL-8 levels did not significantly differ in the supernatants of biopsies cultured with infliximab (mean $64458 \pm 25989 \mathrm{pg} / \mathrm{mL}$ ) in comparison to those with $\lg \mathrm{G} 1$ (mean $33858 \pm 14193$ $\mathrm{pg} / \mathrm{mL}$ ).

\section{Discussion}

Herein this exploratory study, we show an increase in neuroendocrine cells in pouch mucosa. Several studies have reported changes in neuroendocrine cell number in IBD mucosa, including patients with pouch (Table 1). ${ }^{3-11,18-20}$ Nevertheless, the current knowledge on this topic is conflicting due to the use of different counting methods (Table 1) and hormones tested. A high number of neuroendocrine cells has been observed not only in IBD mucosa, ${ }^{5}$ but also in lymphocytic colitis, ${ }^{24-26}$ and in the duodenum of patients with celiac disease. ${ }^{12}$ By enumerating neuroendocrine cells through an accurate method which we already validated in the small bowel mucosa -i.e. counting per 100 crypt cells in well-oriented biopsy specimens-, ${ }^{12}$ we showed an increase in the number of $\mathrm{CgA}$-positive cells in pouch mucosa and IBD ileum. Our data showing a higher number of cells positive for the pan-neuroendocrine marker chromogranin $A(C g A)$ in the ileum of CD patients are in agreement with previous studies. ${ }^{3,4}$ Moreover, there is growing evidence of the pro-inflammatory role of serotonin in gastrointestinal disorders; in particular, serotonin triggers the release of pro-inflammatory cytokines from macrophages. ${ }^{27,28} \mathrm{EC}$ cell hyperplasia has been also observed in lymphocytic colitis, ${ }^{26}$ and in a specific population with irritable pouch syndrome. ${ }^{20}$ According to all these findings, in our series of patients with a pouch and in IBD ileum, serotonin-positive cells were significantly increased compared to controls. Notably, we here describe for the first time an increase of serotonin-positive cells in the inflamed ileum of UC patients and further studies are needed in order to assess a possible independent 
role of these cells in UC-associated ileitis. ${ }^{29}$ All the studies on serotonin-positive cells in UC patients have been conducted in colonic or rectal mucosa and reported controversial data. $5,8-11$ Finally, the presence of dysplasia or cancer leading to proctocolectomy did not influence neither CgA-positive cells nor serotonin-producing cells in pouch mucosa.

As EC cells might be underestimated by immunohistochemistry and may not reflect the increase of serotonin production, we measured serotonin rate-limiting enzyme $\mathrm{TpH}-1$ in the pouch biopsies by quantitative RT-PCR. Besides $\mathrm{TpH}-2$ that is only expressed in human brain, $\mathrm{TpH}-1$ is the only enzyme that synthetizes serotonin, therefore could be considered a reliable indirect measure of serotonin production. ${ }^{29}$ Our results showing higher $\mathrm{TpH}-1$ transcript levels in IBD ileum compared to controls are in keeping with the known pro-inflammatory effects of this molecule and the EC cell hyperplasia identified in this group. $\mathrm{TpH}-1$ transcript levels in patients with pouch are increased compared to controls, but to a level that is just below statistical significance. Moreover, there is a weak negative correlation between the percentage of $\mathrm{CgA}$ positive cells or that of serotonin-positive cells and the degree of acute plus chronic inflammation. Therefore, it is reasonable to assume that the small number of patients with a high degree of pouch inflammation may justify these findings, as well as other possible mechanisms of inflammation we have not looked at in the present study (i.e., dysbiosis, mucosal ischemia, genetic susceptibility, immune dysregulation). ${ }^{31}$ Peripheral $\mathrm{TpH}-1$ inhibitors have been successfully tested in murine models of IBD. ${ }^{32}$ As serotonin is rapidly removed from the interstitial space by enterocytes through SERT, we also detected the mucosal transcripts of this transporter, reported to be reduced in the rectum of UC patients. ${ }^{11}$ However, we did not find any change in the mucosal transcript level of SERT in patients with pouch in comparison to control subjects. We then measured $\mathrm{TpH}-1$ and SERT expression in the pouch biopsies cultured ex vivo with infliximab, an anti-TNF- $\alpha$ monoclonal antibody that has been demonstrated to exert a therapeutic effect on patients with pouchitis. ${ }^{33}$ Nonetheless, infliximab did not modify $\mathrm{TpH}-1$ and 
SERT levels. In order to validate our ex vivo experiments, in the biopsy culture supernatants we detected IL-6, a cytokine of the innate immunity, and IL-8, a chemokine, known to be increased in pouch mucosa. ${ }^{34,35}$ Infliximab was able to reduce both IL-6 and IL-8, although not significantly. A likely explanation for this finding is the lack of statistical power, with the subsequent high risk of $\beta$-error, given that most of the enrolled patients with a pouch only had mild mucosal inflammation. As already mentioned, serotonin causes the release of these cytokines from macrophages $^{28}$ and this may explain the modest efficacy of infliximab that blocks a different pathway of inflammation. Several $5-\mathrm{HT}_{3}$ receptor antagonists have been reported to ameliorate intestinal inflammation, but none of them has been approved so far. ${ }^{36}$ We therefore envisage that future studies will provide new insights to this regard. Finally, in contrast with Schaeffer et al., ${ }^{37}$ none of our pouch biopsies was associated with increased IELs infiltration, and no correlation between IELs count and CgA- or serotonin-positive cells was observed in our pouch biopsies.

In conclusion, neuroendocrine cells are increased in the mucosa of patients with pouch, although no clear correlation was seen with the degree of inflammation, nor with the presence of previous dysplasia. We cannot exclude that the different immunological and microbial luminal milieu in which the "orthotopically-transplanted ileum" is transposed when the pouch is crated might have an influence on the neuroendocrine cell compartment. The significance of this finding is yet to be fully understood, but could represent a future target of intervention. Larger studies are needed to clarify whether the lack of change of $\mathrm{TpH}-1$ and SERT transcript levels may be attributed to a small sample size or to other unexplored causes.

Guarantor of the article: Antonio Di Sabatino

Statement of author contributions: All authors participated in drafting of the manuscript or critical revision of the manuscript for important intellectual content, and provided approval of the 
final submitted version. Individual contributions are as follows. ADS: study concept and design, analysis and interpretation of data, statistical analysis, manuscript preparation, principal investigator, and guarantor. PG: acquisition of data, technical and material support, statistical analysis, manuscript preparation. AV, EB, CK, GB, MM, MVL, NA, MC, RM, PF, MT and FC: acquisition of data, technical and material support. GS and SA: clinical management of patients. ADS and OL: fund raising. GRC: study supervision, fund raising.

Personal acknowledgments: None 


\section{References}

1. El-Salhy M, Hatlebakk JG, Gilja OH. Abnormalities in endocrine and immune cells are correlated in dextran-sulfate-sodium-induced colitis in rats. Mol Med Rep 2017;15:12-20.

2. El-Salhy M, Mazzawi $\mathrm{T}$, Umezawa $\mathrm{K}$, et al. Enteroendocrine cells, stem cells and differentiation progenitors in rats with TNBS-induced colitis. Int J Mol Med 2016;38:1743-51.

3. Bishop AE, Pietroletti R, Taat CW, et al. Increased populations of endocrine cells in Crohn's ileitis. Virchows Arch A Pathol Anat Histopathol 1987;410:391-6.

4. Moran GW, Pennock J, McLaughlin JT. Enteroendocrine cells in terminal ileal Crohn's disease. J Crohns Colitis 2012;6:871-80.

5. El-Salhy M, Danielsson A, Stenling R, et al. Colonic endocrine cells in inflammatory bowel disease. J Intern Med 1997;242:413-9.

6. Gledhill A, Enticott ME, Howe S. Variation in the argyrophil cell population of the rectum in ulcerative colitis and adenocarcinoma. J Pathol 1986;149:287-91.

7. Watanabe $T$, Kubota $\mathrm{Y}$, Sawada $\mathrm{T}$, et al. Distribution and quantification of somatostatin in inflammatory disease. Dis Colon Rectum 1992;35:488-94.

8. Ahonen A, Kyösola K, Penttilä O. Enterochromaffin cells in macrophages in ulcerative colitis and irritable colon. Ann Clin Res 1976;8:1-7.

9. Kyösola K, Penttilä O, Salaspuro M. Rectal mucosal adrenergic innervation and enterochromaffin cells in ulcerative colitis and irritable colon. Scand J Gastroenterol 1977;12:363-7.

10. Verity MA, Mellinkoff SM, Frankland M, et al. Serotonin content and argentaffin and Paneth 
cell changes in ulcerative colitis. Gastroenterology 1962;43:24-31.

11. Coates MD, Mahoney CR, Linden DR, et al. Molecular defects in mucosal serotonin content and decreased serotonin reuptake transporter in ulcerative colitis and irritable bowel syndrome. Gastroenterology 2004;126:1657-64.

12. Di Sabatino A, Giuffrida P, Vanoli A, et al. Increase in neuroendocrine cells in the duodenal mucosa of patients with refractory celiac disease. Am J Gastroenterol 2014;109:258-69.

13. Rindi G, Leiter AB, Kopin AS, et al. The "normal" endocrine cell of the gut: changing concepts and new evidences. Ann N Y Acad Sci 2004;1014:1-12.

14. Stefuli J, Cicin-Sain L, Schauenstein K, Jernej B. Serotonin and immune response effect of the amine on in vitro proliferation of rat lymphocytes. Neuroimmunomodulation 2001;9:1039.

15. Li N, Ghia JE, Wang H, et al. Serotonin activates dendritic cell function in the context of gut inflammation. Am J Pathol 2011;178:662-71.

16. Laberge S, Cruikshank WW, Beer DJ, et al. Secretion of IL-16 (lymphocyte chemoattractant factor) from serotonin-stimulated CD8+ T cells in vitro. J Immunol 1996;156:310-5.

17. Ghia JE, Li N, Wang H, et al. Serotonin has a key role in the pathogenesis of experimental colitis. Gastroenterology 2009;137:1649-60.

18. Greenberg GR, Buchan AM, McLeod RS, et al. Gut hormone responses after reconstructive surgery for ulcerative colitis. Gut 1989;30:1721-30.

19. Pietroletti R, Slors JF, Carlei F, et al. Immunocytochemical study of endocrine cells in pelvic ileal reservoirs. Dis Colon Rectum 1990;33:703-6.

20. Shen B, Liu W, Remzi FH, et al. Enterochromaffin cell hyperplasia in irritable pouch 
syndrome. Am J Gastroenterol 2008;103:2293-300.

21. Shen B, Achkar JP, Lashner BA, et al. Endoscopic and histologic evaluation together with symptom assessment are required to diagnose pouchitis. Gastroenterology 2001;121:261267.

22. Moskowitz RL, Shepherd NA, Nicholls RJ. An assessment of inflammation in the reservoir after restorative proctocolectomy with ileoanal ileal reservoir. Int J Colorectal Dis 1986;1:16774.

23. Naini BV, Cortina G. A histopathologic scoring system as a tool for standardized reporting of chronic (ileo)colitis and independent risk assessment for inflammatory bowel disease. Hum Pathol 2012;43:2187-96.

24. El-Salhy M, Lomholt-Beck B, Gundersen TD. High chromogranin A cell density in the colon of patients with lymphocytic colitis. Mol Med Rep 2011;4:603-5.

25. El-Salhy M, Gundersen D, Hatlebakk JG, et al. Chromogranin A cell density as a diagnostic marker for lymphocytic colitis. Dig Dis Sci 2012;57:3154-9.

26. El-Salhy M, Gundersen D, Hatlebakk JG, et al. High densities of serotonin and peptide YY cells in the colon of patients with lymphocytic colitis. World J Gastroenterol 2012;18:6070-5.

27. Khan WI, Ghia JE. Gut hormones: emerging role in immune activation and inflammation. Clin Exp Immunol 2010;161:19-27.

28. Ghia JE, Li N, Wang H, et al. Serotonin has a key role in pathogenesis of experimental colitis. Gastroenterology 2009;137:1649-60.

29. Patil DT, Odze RD. Backwash is hogwash: the clinical significance of ileitis in ulcerative colitis. Am J Gastroenterol 2017;112:1211-4. 
30. Walther DJ, Peter JU, Bashammakh S, et al. Synthesis of serotonin by a second tryptophan hydroxylase isoform. Science. 2003;299:76.

31. Schieffer KM, Williams ED, Yochum GS, et al. Review article: the pathogenesis of pouchitis. Aliment Pharmacol Ther 2016;44:817-35.

32. Margolis KG, Stevanovic K, Li Z, et al. Pharmacological reduction of mucosal but not neuronal serotonin opposes inflammation in mouse intestine. Gut 2014;63:928-37.

33. Kelly $\mathrm{OB}$, Rosenberg $M$, Tyler $A D$, et al. Infliximab to treat refractory inflammation after pelvic pouch surgery for ulcerative colitis. J Crohns Colitis 2016;10:410-7.

34. Gionchetti P, Campieri M, Belluzzi A, et al. Mucosal concentrations of interleukin-1 beta, interleukin-6, interleukin-8, and tumor necrosis factor-alpha in pelvic ileal pouches. Dig Dis Sci 1994;39:1525-31.

35. Patel RT, Bain I, Youngs D, et al. Cytokine production in pouchitis is similar to that in ulcerative colitis. Dis Colon Rectum 1995;38:831-7.

36. Kato S. Role of serotonin 5- $\mathrm{HT}_{3}$ receptors in intestinal inflammation. Biol Pharm Bull 2013;36:1406-9.

37. Schaeffer DF, Walsh JC, Tyler AD, et al. Intraepithelial lymphocytosis is a frequent finding in biopsies from ileal pouch-anal anastomoses. Hum Pathol 2016;54:31-6. 


\section{Figure legend}

Figure 1. A-H. Immunohistochemical detection of chromogranin $\mathrm{A}(\mathrm{CgA})$ and serotonin. The immunohistochemical detection of $\mathrm{CgA}$ showed numerous $\mathrm{CgA}$-positive cells in the pouch mucosa of a patient undergoing restorative proctocolectomy and ileal pouch-anal anastomosis for ulcerative colitis (A) and in the ileal crypt epithelium of a patient with active ulcerative colitis (B) and Crohn's disease (C). On the contrary, CgA positivity was limited to a few cells in the ileal crypt epithelium of a control subject (D). Serotonin immunostaining revealed numerous positive cells in the pouch mucosa of the patient shown in $A(E)$, in the ileal mucosa of the patients with ulcerative colitis shown in $B(F)$ and Crohn's disease shown in $C(G)$, compared with serotoninpositive cells in the ileal crypt epithelium of the control subject shown in $D(H)$. Data are representative of staining performed in the pouch of 17 patients undergoing restorative proctocolectomy, and in the ileum of 17 patients with active inflammatory bowel disease and 16 control subjects.

Figure 2. A-B. Number of chromogranin A(CgA)-positive cells and serotonin-positive cells counted per 100 crypt cells, and their correlation. Number of CgA-positive cells (A) and serotonin-positive cells (B), both counted per 100 crypt cells, in the pouch mucosa of 17 patients undergoing restorative proctocolectomy and ileal pouch-anal anastomosis for ulcerative colitis, and in the ileal crypt epithelium of 17 patients with active inflammatory bowel disease (IBD) and 16 control subjects. Horizontal bars represent mean values. (C) Significant positive correlation between the number of chromogranin $\mathrm{A}(\mathrm{CgA})$-positive cells per 100 crypt cells and the number of serotonin-positive cells per 100 crypt cells.

Figure 3. A-B. Tryptophan hydroxylase $(\mathrm{TpH})-1$ and serotonin-selective reuptake 
transporter (SERT) transcripts. (A) $\underline{T p H}-1$ and (B) SERT transcripts, measured by quantitative RT-PCR, in the pouch mucosa of six patients undergoing restorative proctocolectomy and ileal pouch-anal anastomosis for ulcerative colitis, and in the ileal mucosa of six patients with active inflammatory bowel disease (IBD), and seven control subjects. The values, normalized for GAPDH and representing the fold change in transcript expression compared to control subjects, are reported as means.

Figure 4. A-B. Effect of infliximab on the pouch mucosa grown ex vivo. (A) Tryptophan hydroxylase (TpH)-1 and serotonin-selective reuptake transporter (SERT) transcripts, measured by quantitative RT-PCR, in organ culture pouch biopsies collected from five patients undergoing restorative proctocolectomy and ileal pouch-anal anastomosis for ulcerative colitis and cultured for $24 \mathrm{~h}$ with $\lg \mathrm{G} 1$ or infliximab. The values, normalized for GAPDH and representing the fold change in transcript expression compared to IgG1, are reported as means. (B) Interleukin (IL)6 and IL-8 concentrations were detected by ELISA in the supernatants of the same organ culture biopsies used for quantitative RT-PCR for TpH-1 and SERT. Results are reported as means. 

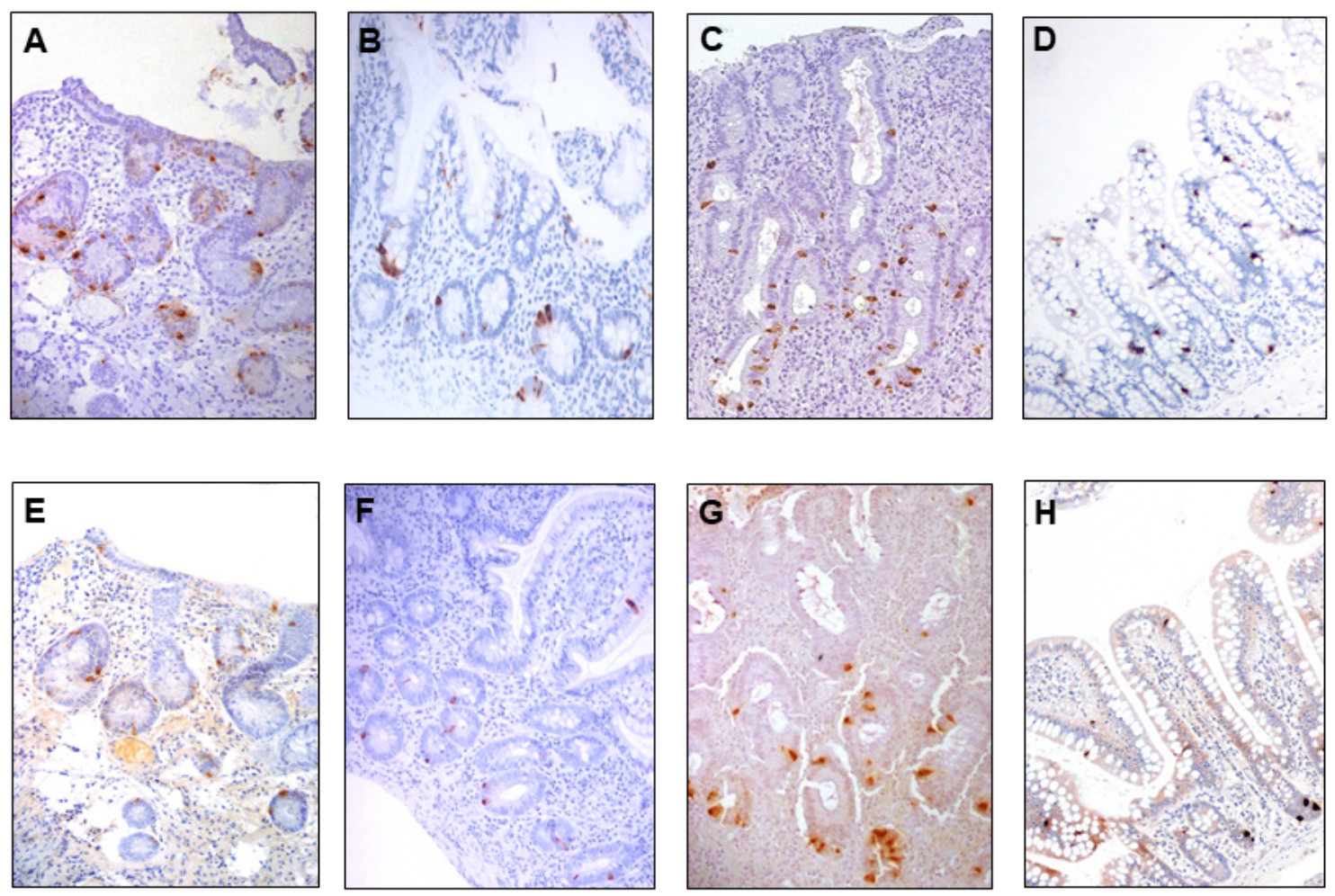

Figure 1 
A

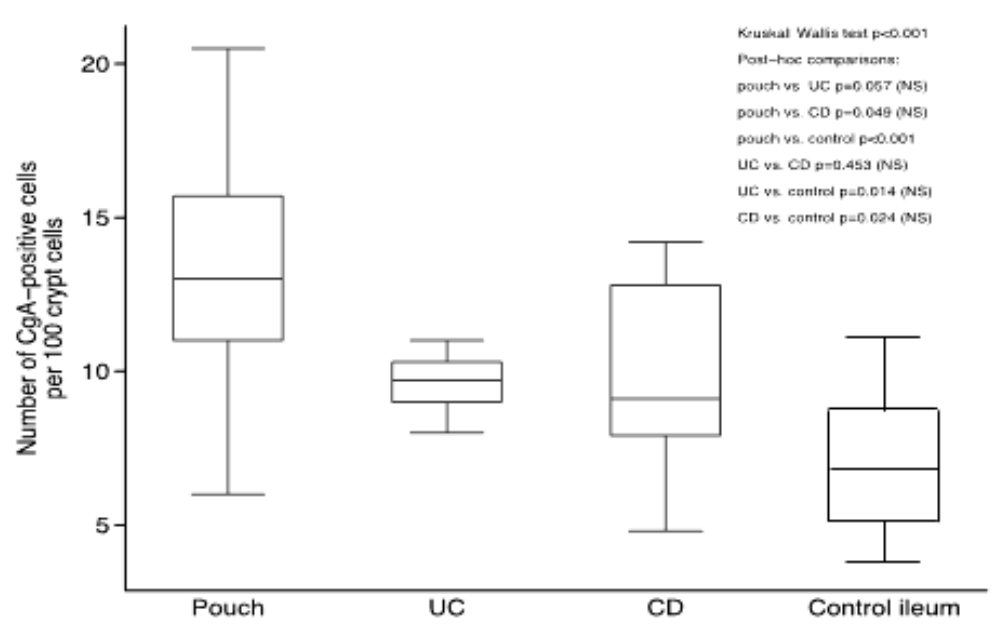

B

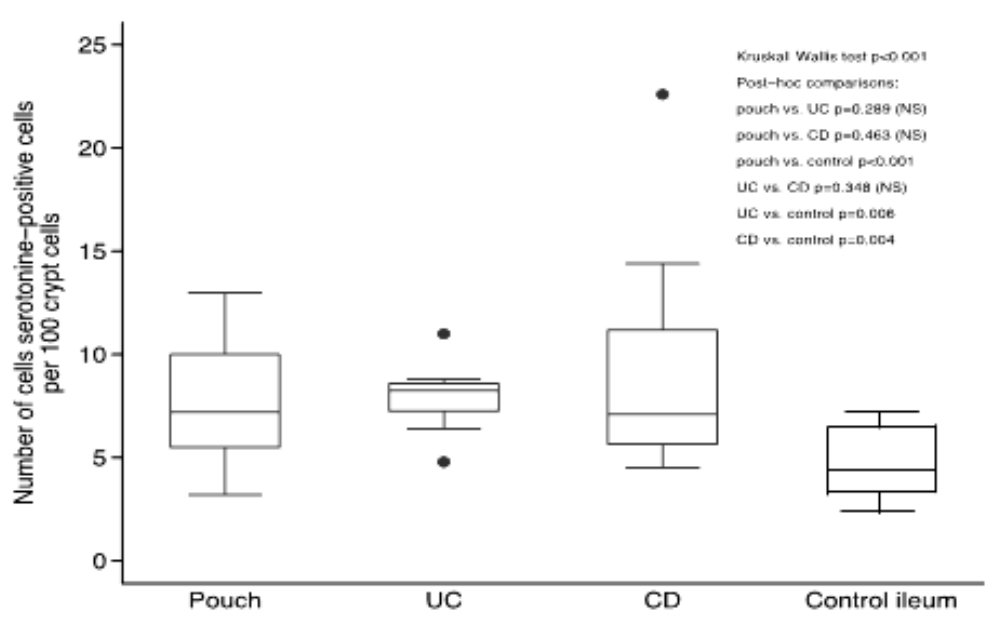

C

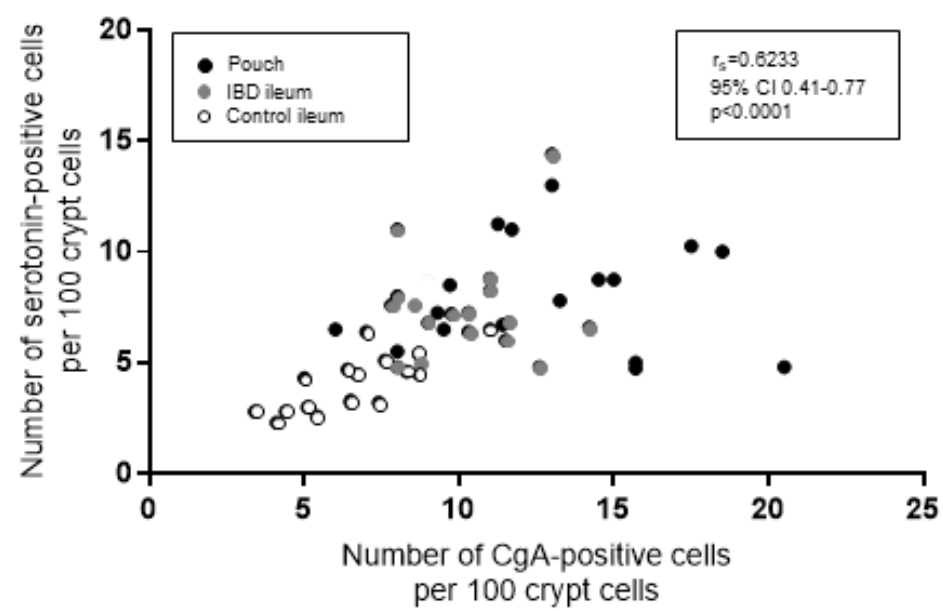

Figure 2 

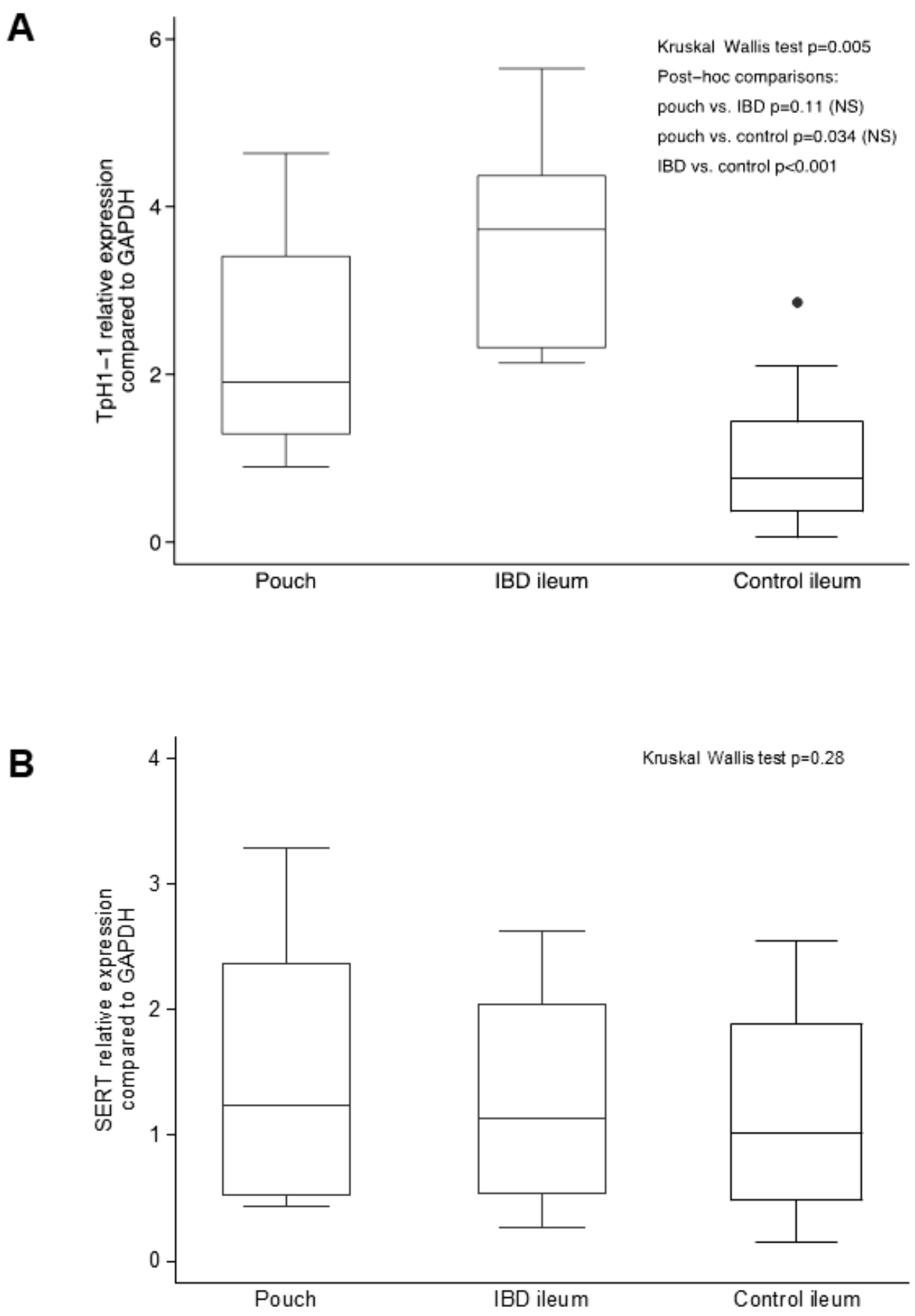

Figure 3 
A

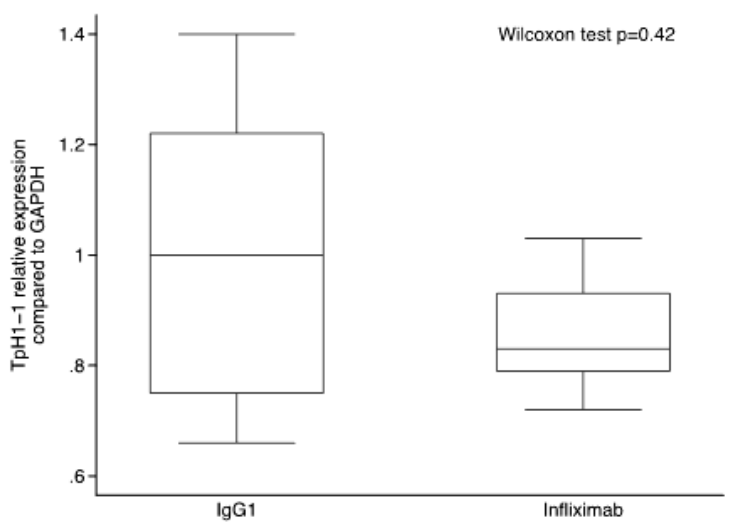

B

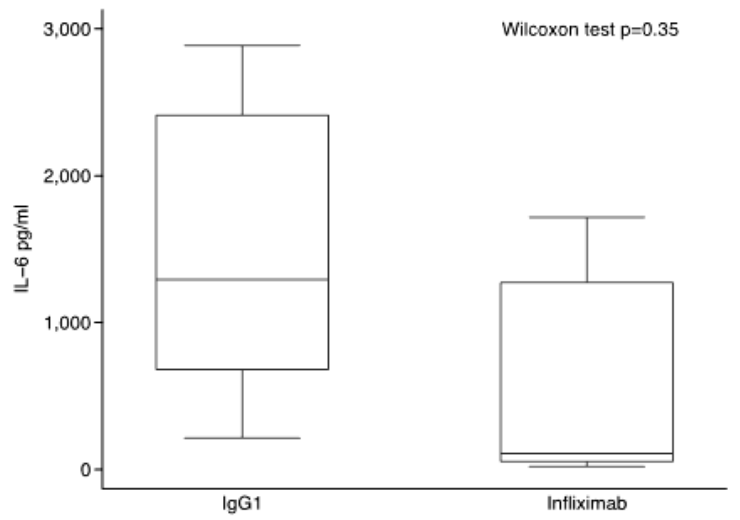

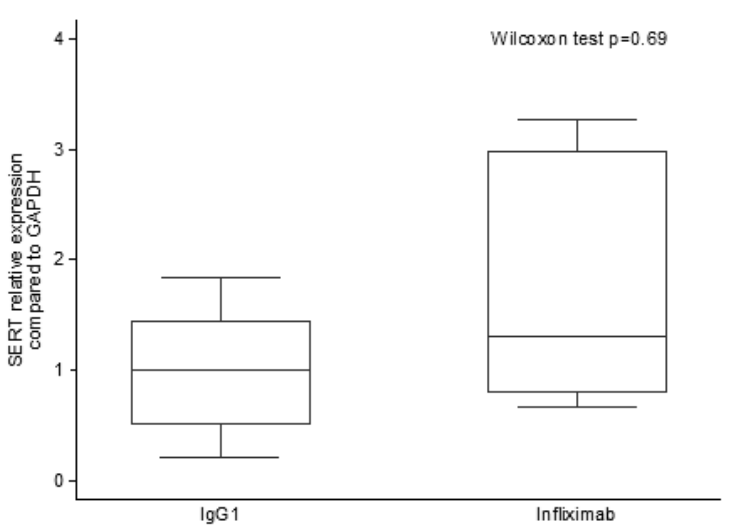

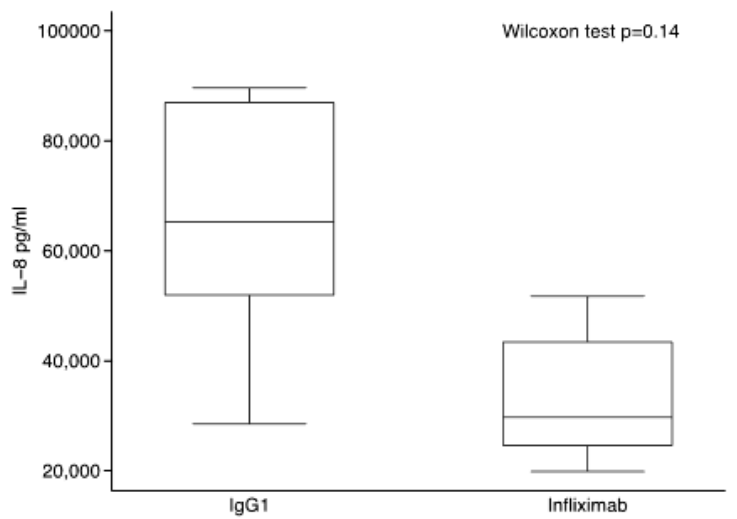

Figure 4 
Table 1. Studies analyzing neuroendocrine cells in inflammatory bowel disease

\begin{tabular}{|c|c|c|c|c|c|c|}
\hline Authors & $\begin{array}{l}\text { Disease } \\
\text { type }\end{array}$ & $\mathbf{N}$ & Site & Detection method & Counting method & Findings \\
\hline Greenberg et al. ${ }^{18}$ & Pouchitis & 12 & Pouch & $\begin{array}{l}\text { IHC for neurotensin, enteroglucagon and } \\
\text { PYY }\end{array}$ & Per mm of epithelium & $\begin{array}{l}\text { Decrease in neurotensin-, enteroglucagon- and PYY-positive cells } \\
\text { in pouch mucosa (compared to normal ileal mucosa) }\end{array}$ \\
\hline Pietroletti et al. ${ }^{19}$ & Pouchitis & 9 & Pouch & $\begin{array}{l}\mathrm{IHC} \text { for } \mathrm{CgA} \text {, enteroglucagon, serotonin, } \\
\text { PYY, neurotensin and somatostatin }\end{array}$ & Per visual field $(x 10)$ & $\begin{array}{l}\text { Decrease in neurotensin-, enteroglucagon-, PYY-positive cells in } \\
\text { pouch mucosa (compared to normal ileal mucosa). No difference } \\
\text { of CgA- and somatostatin-positive }\end{array}$ \\
\hline Shen B et al. ${ }^{20}$ & IPS & 36 & Pouch & $\mathrm{IHC}$ for serotonin & $\begin{array}{l}\text { Per } 4200 \text { epithelial } \\
\text { cells }\end{array}$ & $\begin{array}{l}\text { Increase in serotonin-positive cells in IPS (compared to normal } \\
\text { pouch mucosa) }\end{array}$ \\
\hline Verity et al. ${ }^{10}$ & UC & 8 & Colon & Gomori silver technique and diazo method & Per 100 crypts & $\begin{array}{l}\text { Decrease in serotonin-positive cells in UC (compared to normal } \\
\text { colonic mucosa) }\end{array}$ \\
\hline Watanabe et al. ${ }^{7}$ & UC & 25 & Colon & $\mathrm{IHC}$ for somatostatin & $\begin{array}{l}\text { Per } 1000 \text { epithelial } \\
\text { cells }\end{array}$ & $\begin{array}{l}\text { Decrease in somatostatin-positive cells in CD (compared to } \\
\text { normal colonic mucosa) }\end{array}$ \\
\hline El-Salhy et al. ${ }^{5}$ & UC & 17 & Colon & $\begin{array}{l}\mathrm{IHC} \text { for } \mathrm{CgA} \text {, enteroglucagon, serotonin, PYY } \\
\text { and PP }\end{array}$ & $\begin{array}{l}\text { Area of positive } \\
\text { cells/area of epithelial } \\
\text { cells }\end{array}$ & $\begin{array}{l}\text { Increase in CgA- and serotonin-positive cells in UC (compared to } \\
\text { normal colonic mucosa) }\end{array}$ \\
\hline Ahonen et al. ${ }^{8}$ & UC & 6 & Rectum & $\begin{array}{l}\text { Formaldehyde-induced fluorescence after } \\
\text { freeze-drying and Epon embedding }\end{array}$ & Per crypt & $\begin{array}{l}\text { Decrease in serotonin-positive cells in UC (compared to normal } \\
\text { rectal mucosa) }\end{array}$ \\
\hline Kyösola et al. ${ }^{9}$ & UC & 13 & Rectum & $\begin{array}{l}\text { Glyoxylic-acid-induced fluorescence } \\
\text { histochemical method }\end{array}$ & $\begin{array}{l}\text { On a scale from } 0 \text { to } \\
10\end{array}$ & $\begin{array}{l}\text { Decrease in serotonin-positive cells in UC (compared to normal } \\
\text { rectal mucosa) }\end{array}$ \\
\hline Gledhill et al. ${ }^{6}$ & UC & 10 & Rectum & Grimelius's silver impregnation & $\begin{array}{l}\text { Per crypt or mm of } \\
\text { epithelium or mm of } \\
\text { muscularis mucosae }\end{array}$ & $\begin{array}{l}\text { Increase in neuroendocrine cells in UC (compared to normal } \\
\text { rectal mucosa) }\end{array}$ \\
\hline Coates et al. ${ }^{11}$ & UC & 22 & Rectum & $\mathrm{IHC}$ for $\mathrm{CgA}$ and serotonin & $\begin{array}{l}\text { Per mm of muscularis } \\
\text { mucosae }\end{array}$ & $\begin{array}{l}\text { Decrease in serotonin-positive cells in UC (compared to normal } \\
\text { rectal mucosa) }\end{array}$ \\
\hline Bishop et al. ${ }^{3}$ & CD & 10 & lleum & $\begin{array}{l}\text { IHC for } \mathrm{CgA} \text {, glucagon ( } \mathrm{N} \text {-terminal), } \\
\text { somatostatin, neurotensin and } \mathrm{PYY}\end{array}$ & $\begin{array}{l}\text { Permm of muscularis } \\
\text { mucosae }\end{array}$ & $\begin{array}{l}\text { Increase in CgA-positive and serotonin-positive cells (compared to } \\
\text { normal ileal mucosa) }\end{array}$ \\
\hline Moran et al. ${ }^{4}$ & CD & 38 & Ileum & $\begin{array}{l}\text { IHC for CgA and PYY; } \\
\text { immunofluorescence for GLP-1 }\end{array}$ & $\begin{array}{l}\text { Per villous-crypt } \\
\text { unit/HPF }\end{array}$ & $\begin{array}{l}\text { Increase in CgA-positive and GLP-1-positive cells, but not in PYY- } \\
\text { positive cells (compared to normal ileal mucosa) }\end{array}$ \\
\hline
\end{tabular}

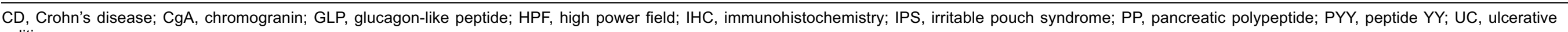
colitis. 
Table 2. Clinical, endoscopic and pathological features of 17 patients undergoing restorative proctocolectomy and ileal pouch-anal anastomosis for ulcerative colitis

\begin{tabular}{|c|c|c|c|c|c|c|c|c|c|c|c|}
\hline \multirow[t]{2}{*}{$\mathbf{P t}$} & \multirow[t]{2}{*}{ Sex } & \multirow{2}{*}{$\begin{array}{l}\text { Age } \\
(y r)\end{array}$} & \multirow{2}{*}{$\begin{array}{l}\text { Age at UC } \\
\text { diagnosis } \\
\text { (yr) }\end{array}$} & \multirow{2}{*}{$\begin{array}{l}\text { Age at } \\
\text { proctocolectomy } \\
\text { (yr) }\end{array}$} & \multirow{2}{*}{$\begin{array}{l}\text { Smoking } \\
\text { habit }\end{array}$} & \multirow{2}{*}{$\begin{array}{l}\text { Reasons leading to } \\
\text { proctocolectomy }\end{array}$} & \multirow{2}{*}{$\begin{array}{l}\text { Endoscopic } \\
\text { Inflammation } \\
\text { according to } \\
\text { PDAl }\end{array}$} & \multicolumn{3}{|c|}{ Moskowitz criteria } & \multirow{2}{*}{$\begin{array}{l}\text { IELs } \\
(\%)\end{array}$} \\
\hline & & & & & & & & $\begin{array}{l}\text { Acute } \\
(0-6)\end{array}$ & $\begin{array}{l}\text { Chronic } \\
(0-6)\end{array}$ & $\begin{array}{l}\text { Total } \\
(0-12)\end{array}$ & \\
\hline 1 & $\mathrm{~F}$ & 44 & 34 & 39 & Smoker & Unresponsive to medical treatment & 0 & 1 & 2 & 3 & 6.5 \\
\hline 2 & $\mathrm{~F}$ & 46 & 25 & 41 & Never smoker & Unresponsive to medical treatment & 0 & 1 & 5 & 6 & 5.4 \\
\hline 3 & M & 56 & 33 & 52 & Past smoker & Dysplasia & 2 & 3 & 4 & 7 & 6.0 \\
\hline 4 & M & 28 & 15 & 23 & Past smoker & Toxic megacolon & 1 & 1 & 5 & 6 & 3.4 \\
\hline 5 & M & 57 & 45 & 53 & Never smoker & Unresponsive to medical treatment & 2 & 3 & 6 & 9 & 5.2 \\
\hline 6 & $\mathrm{~F}$ & 61 & 28 & 58 & Smoker & Dysplasia & 2 & 3 & 5 & 8 & 10.2 \\
\hline 7 & $\mathrm{~F}$ & 26 & 17 & 22 & Never smoker & Unresponsive to medical treatment & 3 & 4 & 6 & 10 & 4.0 \\
\hline 8 & $\mathrm{~F}$ & 40 & 32 & 37 & Never smoker & Unresponsive to medical treatment & 2 & 1 & 5 & 6 & 4.0 \\
\hline 9 & $\mathrm{~F}$ & 40 & 22 & 35 & Never smoker & Unresponsive to medical treatment & 2 & 1 & 2 & 3 & 5.8 \\
\hline 10 & M & 43 & 10 & 37 & Past smoker & Dysplasia & 1 & 1 & 5 & 6 & 3.0 \\
\hline 11 & M & 42 & 38 & 40 & Past smoker & Unresponsive to medical treatment & 0 & 1 & 4 & 5 & 5.2 \\
\hline 12 & M & 64 & 61 & 62 & Never smoker & Unresponsive to medical treatment & 2 & 1 & 5 & 6 & 4.6 \\
\hline 13 & M & 28 & 26 & 32 & Past smoker & Toxic megacolon & 1 & 1 & 4 & 5 & 9.8 \\
\hline 14 & $\mathrm{~F}$ & 63 & 40 & 58 & Past smoker & Cancer $\left(\mathrm{T}_{1} \mathrm{~N}_{0}\right)$ & 3 & 3 & 5 & 8 & 2.2 \\
\hline 15 & $\mathrm{~F}$ & 45 & 28 & 39 & Smoker & Unresponsive to medical treatment & 2 & 1 & 5 & 6 & 5.6 \\
\hline 16 & M & 37 & 26 & 32 & Past smoker & Unresponsive to medical treatment & 3 & 3 & 2 & 5 & 6.6 \\
\hline 17 & M & 64 & 59 & 60 & Never smoker & Unresponsive to medical treatment & 3 & 6 & 6 & 12 & 11.4 \\
\hline
\end{tabular}

F, female; IEL, intraepithelial lymphocyte; M, male; PDAI, Pouchitis Disease Activity Index; Pt, patient; UC, ulcerative colitis; yr, years. 